\title{
Synthesis of urea after stimulation with amino acids: relation to liver function
}

\author{
H VILSTRUP \\ From Rigshospitalet, Division of Hepatology, Copenhagen, Denmark
}

SUMMARY Hepatic urea synthesis is the organism's main channel for the disposal of nitrogen and it may be an 'essential' liver function. In six control subjects and five patients with cirrhosis of the liver urea synthesis was studied during continuous infusion for six to 24 hours of about $3 \mathrm{mmol} \alpha$-amino nitrogen $/ \mathrm{h} \times \mathrm{kg}$ body weight. The urea synthesis rate was calculated in intervals of two hours as urinary excretion with correction for accumulation in the total body water and for hydrolysis of urea in the gut. The peripheral venous plasma $\alpha$-amino nitrogen concentration increased from 3 to about $14 \mathrm{mmol} / \mathrm{l}$ and the urea nitrogen synthesis rate from 25 to about $215 \mathrm{mmol} / \mathrm{h}$. In all cases the urea synthesis rate rose linearly with the $\alpha$-amino concentration throughout the examined range. The slope of this linear relationship is an expression of the hepatic conversion of $\alpha$-amino nitrogen to urea nitrogen ('functional hepatic nitrogen clearance'). The functional hepatic nitrogen clearance was $22.4 \mathrm{l} / \mathrm{h}$ in control subjects and $13.7 \mathrm{l} / \mathrm{h}(\mathrm{P}<0.025)$ in the patients with cirrhosis. It was correlated with quantitative measures of the liver function (the galactose elimination capacity, $r=0 \cdot 84$, and the clearance of antipyrine, $r=0.80$ ). These observations, while confirming the abundant capacity of the urea synthesis system, imply that a given urea synthesis rate requires a higher $\alpha$-amino level in patients with reduced liver function.

(1)

Synthesis of urea is the body's major way of eliminating excess nitrogen. The enzymes catalysing the single steps of urea synthesis are found in virtually all tissues, but only in the liver in such quantities and intraorganelle localisations that the urea cycle is operational. ${ }^{1}$ Only one patient with completely extinct urea synthesis has ever been reported, ${ }^{2}$ and a limited capacity for urea synthesis is frequently taken to play a pathogenetic part in hepatic encephalopathy. ${ }^{34}$ Thus urea synthesis may in itself be an 'essential' liver function-that is, essential for the sustenance of life and health.

The aim of the present investigation was to study urea synthesis in man after stimulation with amino acids, and to evaluate its relation to liver function.

\section{Methods}

\section{SUBJECTS}

The subjects were six control individuals with no sign or symptom of liver disease, and five patients with biopsy proven cirrhosis of the liver. All had normal serum creatinine values. Table 1 gives clinical and laboratory data.

Address for correspondence: $H$. Vilstrup, MD, Rigshospitalet, 2151, Blegdamsvej 9, DK-2100 Copenhagen, Denmark.

Received for publication 29 July 1980
Body weight, diet, and clinical condition were unchanged during the time used for the examinations. The mean body weight was identical in both groups. Age was, on average, $55 \%$ lower in the control group. Control subject no. 2 had been taking $25 \mathrm{mg}$ diazepam per day and $10 \mathrm{mg}$ nitrazepam per day for several months, and $200 \mathrm{mg}$ amitriptyline per day for three weeks before the investigation, and his clearance of antipyrine is not included. The remaining control subjects did not take drugs regularly. All patients except no. 11 had suffered from hepatic coma or ascites. Patient no. 9 had slight ascites at the time of investigation. Patient no. 7 was treated with prednisone $5 \mathrm{mg}$ per day. Informed consent was obtained in all cases.

The subjects were fasted for 15 hours before and during the investigation. Amino acids were given as a continuous intravenous infusion of Intramin $11 \%$ (Vitrum $\dagger$ ) by a volumetric infusion pump (Valleylab). The mixture, which contains $975 \mathrm{mmol} / 1$

\footnotetext{
+Composition of Intramin $11 \%$ (Vitrum measured on a Durrum 500 amino acid autoanalyser (numbers are concentrations in $\mathrm{mmol} / \mathrm{l}$ of the mentioned $L \alpha$-amino acids): aspartic acid 66 , threonine 33 , serine 48 , proline 89 , glycine 142 , alanine 187 , valine 49 , methionine 54 , isoleucine 38 , leucine 62 , phenylalanine 49 , tryptophan 13 , lysine 39 , histidine 40 , arginine 62 . The mixture was free from urea ${ }^{5}$ and ammonia, ${ }^{7}$ measured by the methods indicated.
} 
Table 1 Clinical and laboratory data of six control subjects and five patients with cirrhosis of liver

\begin{tabular}{|c|c|c|c|c|c|}
\hline Subject no. & Age $(y r) \operatorname{sex}$ & Bodyweight ( $\mathrm{kg}$ ) & Diagnosis & $\begin{array}{l}\text { Galactose } \\
\text { elimination } \\
\text { capacity } \\
(\text { mmol/min) }\end{array}$ & $\begin{array}{l}\text { Clearance of } \\
\text { antipyrine }(\mathrm{ml} / \mathrm{min})\end{array}$ \\
\hline 1 & $30 \mathbf{M}$ & 91 & Control & $3 \cdot 6$ & 46 \\
\hline 2 & $46 \mathrm{M}$ & 86 & Control: endogenous depression & $3 \cdot 1$ & 一 \\
\hline 3 & $20 \mathrm{~F}$ & 106 & Control: obesity & $2 \cdot 4$ & 38 \\
\hline 4 & $30 \mathbf{M}$ & 84 & Control & $2 \cdot 3$ & 49 \\
\hline 6 & $28 \mathrm{~F}$ & 64 & Control & $2 \cdot 6$ & 31 \\
\hline 7 & $63 \mathrm{~F}$ & 60 & Idiopathic cirrhosis, portocaval shunt & $1 \cdot 0$ & 15 \\
\hline 8 & $67 \mathrm{M}$ & 85 & Alcoholic cirrhosis & $2 \cdot 2$ & 36 \\
\hline 9 & $30 \mathrm{M}$ & 86 & Alcoholic cirrhosis & 1.9 & 23 \\
\hline 10 & $55 \mathrm{M}$ & 85 & Alcoholic cirrhosis & $1 \cdot 3$ & 10 \\
\hline 11 & $57 \mathrm{~F}$ & 44 & Primary biliary cirrhosis & 1.4 & 15 \\
\hline
\end{tabular}

of $\alpha$-amino nitrogen, was infused for six hours (no. 1), 24 hours (nos. 2, 7, and 8), and 12 hours (all other cases) at an average rate of $3.12 \mathrm{mmol} / \mathrm{h} \times$ $\mathrm{kg}$ body weight (range $2 \cdot 55-3.58$ ) in the control subjects, and $2.69 \mathrm{mmol} / \mathrm{h} \times \mathrm{kg}$ body weight (range 2.38-2.91) in the patients with cirrhosis. These perfusion rates were chosen, because they are well tolerated according to Rudman et al. ${ }^{4 \mathrm{a}}$

About five hours after start of the infusion all subjects complained of nausea, and seven vomited. No other side-effect was observed. The loss of urea in the vomit was less than $3 \mathrm{mmol}$ and is not included in the calculations. High diuresis, on the average $0.3 \mathrm{l} / \mathrm{h}$ (range $0.118-0.747$ ), was maintained by giving $0.125-0.5 \mathrm{l} / \mathrm{h}$ of water, orally as tap water, and intravenously as hypotonic (189 mosm/l) $\mathrm{NaCl} /$ lactate (nos. 4, 5, and 6), isotonic glucose/ $\mathrm{NaCl}$ (No. 3), or isotonic glucose (no. 10). The bladder was emptied quantitatively by voiding at intervals of one to four hours (mean 1.9 h). Simultaneously blood samples were drawn from a vein in the arm contralateral to the one in which the infusions were given.

Urea nitrogen in urine and plasma was measured by the urease Berthelot method (coefficient of variation $0.97 \%),{ }^{5}$ and $\alpha$-amino nitrogen by the dinitrofluorobenzene method (coefficient of variation $1 \cdot 25 \%)^{6}$. Blood glucose was measured enzymatically. Blood ammonia was determined before the infusion, six hours after it started, ${ }^{2}$ and 12 hours after it ended. Samples were iced immediately after collection and measured by the glutamate dehydrogenase method ${ }^{7}$ less than 30 minutes after sampling. Liver function was measured less than one week before the examination by the galactose elimination capacity, ${ }^{8}$ and the clearance of antipyrine ${ }^{9}$ (Table 1 ).

\section{CALCULATIONS}

The urea synthesis rate was calculated for each sampling interval as excretion rate in the urine, corrected for changes in concentration in total body water, and for intestinal hydrolysis with hepatic resynthesis, according to the equation $(\mathrm{E}+\mathrm{A}) / 1-\mathrm{L}$, where $E=$ (urine flow, $1 / h) \times($ urinary urea-N, $\mathrm{mmol} / \mathrm{l}), \mathrm{A}=($ change in blood urea $-\mathrm{N}, \mathrm{mmol} / \mathrm{l} \times \mathrm{h})$ $\times$ (total body water, litres), and $L=$ the fractional loss of newly synthesised urea in the gut.

The total body water was estimated as the volume of distribution of antipyrine ${ }^{10}$ less than one week before the examination. It amounted to $55 \%$ of the body weight in both groups (Table 3 ).

L was estimated in each subject less than one week

Table 2 Peripheral plasma concentrations, urinary excretion rates, and calculated urea synthesis rate before and at end of infusion of amino acids to six control subjects and five patients with cirrhosis of liver

\begin{tabular}{|c|c|c|c|c|c|c|}
\hline & \multicolumn{3}{|c|}{ Before start of infusion } & \multicolumn{3}{|c|}{ At end of infusion } \\
\hline & Control & Cirrhosis & P value ( $t$ test) & Control & Cirrhosis & P value ( $t$ test) \\
\hline $\begin{array}{l}\text { Plasma } \alpha \text {-amino nitrogen } \\
\text { concentration }(\mathrm{mmol} / \mathrm{l})\end{array}$ & $2 \cdot 56 \pm 0 \cdot 25$ & $3 \cdot 50 \pm 0.25$ & $<0.0001$ & $12 \cdot 00 \pm 1 \cdot 77$ & $16 \cdot 37 \pm 5 \cdot 50$ & NS \\
\hline $\begin{array}{l}\text { Plasma urea nitrogen } \\
\text { concentration }(\mathrm{mmol} / \mathrm{l})\end{array}$ & $9 \cdot 25 \pm 2 \cdot 26$ & $12 \cdot 98 \pm 4 \cdot 76$ & NS* & $27 \cdot 38 \pm 8 \cdot 11$ & $40 \cdot 48 \pm 13 \cdot 01$ & $<0.05$ \\
\hline $\begin{array}{l}\text { Urinary urea nitrogen } \\
\text { excretion rate }(\mathrm{mmol} / \mathrm{h})\end{array}$ & $27 \cdot 18 \pm 7 \cdot 83$ & $24 \cdot 02 \pm 5 \cdot 08$ & NS & $164 \cdot 00 \pm 39 \cdot 30$ & $94 \cdot 62 \pm 39 \cdot 72$ & $<0.01$ \\
\hline $\begin{array}{l}\text { Urinary } \alpha \text {-amino nitrogen } \\
\text { excretion rate }(\mathrm{mmol} / \mathrm{h})\end{array}$ & $1 \cdot 18 \pm 0 \cdot 20$ & $0.68 \pm 0.25$ & $<0.05$ & $33 \cdot 85 \pm 22 \cdot 72$ & $17 \cdot 76 \pm 16 \cdot 08$ & NS \\
\hline Urea nitrogen synthesis rate $(\mathrm{mmol} / \mathrm{h})$ & $27 \cdot 15 \pm 12 \cdot 46$ & $25 \cdot 39 \pm 6 \cdot 77$ & NS & $247.58 \pm 48.94$ & $177 \cdot 33 \pm 38 \cdot 85$ & $<0.025$ \\
\hline
\end{tabular}

Not significant, $P>0.05$

Values are given as mean \pm SD. 
Table 3 Total body water (TBW) in per cent of body weight (BW), fractional loss of newly synthesised urea in gut, and linear regression analyses of urea nitrogen synthesis rate (UNSR mmol/h) on peripheral plasma alpha-amino nitrogen concentration (AAN mmol/h) in six control subjects and five patients with cirrhosis of liver

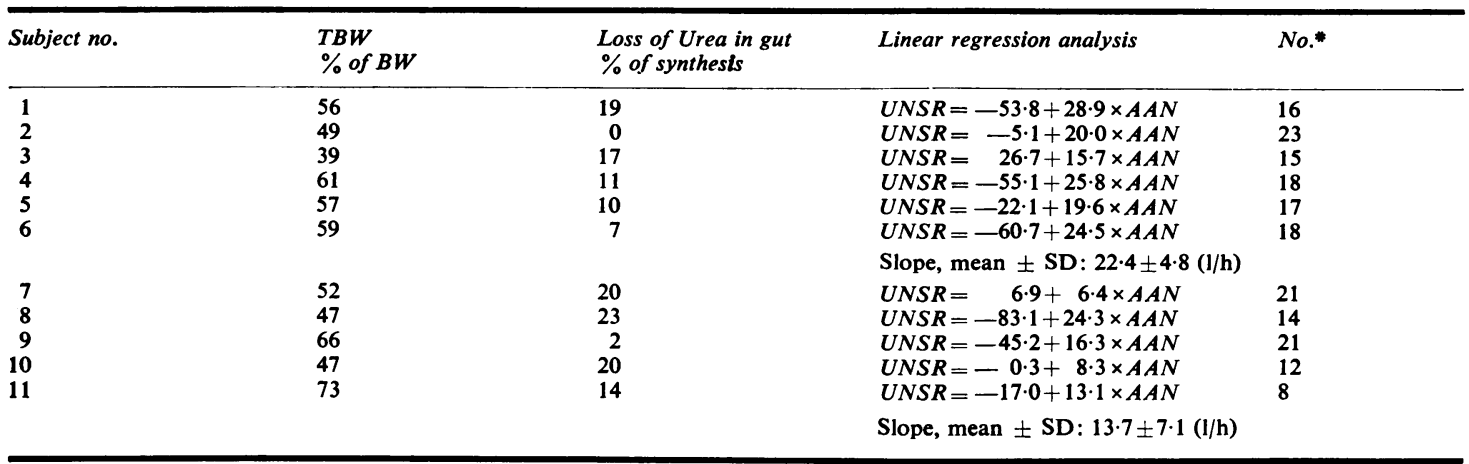

- Number of determinations.

before the examination as follows: $4 \mu \mathrm{Ci}{ }^{14} \mathrm{C}$-urea was injected intramuscularly, and urine was collected in daily aliquots. Radioactive urea in the urine specimens was measured after decolouration with hydrogen peroxyde, dioxane, and Soluene by counting in Instagel by a liquid scintillation counter (Tricarb). L was calculated as the fraction of injected radioactivity not recovered in the urine. ${ }^{11}$ It was, on average, $13 \%$ (Table 3 ).

\section{Results}

Table 2 gives the mean plasma concentrations and urinary excretion rates before the infusion, and the values obtained at the end of infusion-that is, after six, 12 , or 24 hours.

The initial plasma $\alpha$-amino nitrogen concentration was $37 \%$ higher in the patients with cirrhosis than in the control subjects. During the infusion it rose rapidly for the first four hours, later more slowly. Final concentrations were identical in both groups and 4.7 times higher than initial values. After end of the infusion the concentration had returned to the initial level after 14 hours (range nine to 25). Blood urea nitrogen concentration rose threefold in both groups. The rise was nearly linear for the first eight to 12 hours, thereafter relatively smaller. The decline was slow, so that in no case was blood urea nitrogen back to initial concentrations 24 hours after the end of the infusion.

Urinary urea nitrogen excretion rate (Table 2) rose on the average six times in the control subjects and four times in the patients with cirrhosis. In nos. $3,4,5,7$, and 11 a constant excretion rate was approximated after 6.5 hours (range two to 12 hours). When the infusion ended the accumulated urea was excreted but in none of the cases had the excretion rate returned to initial rate 24 hours after the end of the infusion.

Urinary $\alpha$-amino nitrogen excretion rate showed the same relative increase ( 25 to 30 times) in both groups.

Before the infusion urea nitrogen synthesis rate was the same in both groups (Table 2). During the infusion it rose nine times in the control subjects and seven times in the patients with cirrhosis. After the end of the infusion it was back to the initial value after 14 hours (range nine to 25 hours). When the infusion ended accumulation of urea in the total body water contributed on the average $43 \%$ of the urea nitrogen synthesis rate (range 30-68) in both groups. With declining plasma urea nitrogen the accumulation was negative.

Initially, the plasma ammonia concentration was $19 \mu \mathrm{mol} / \mathrm{l}$ (SD:4) and $45 \mu \mathrm{mol} / 1$ (SD:15) in the controls and the patients, respectively $(\mathrm{P}<0.0025)$. Six hours after the infusion began it was 2.6 times higher in both groups, and 12 hours after the end of the infusion it was back to the initial value in all subjects. No consistent change was seen in the plasma glucose concentration.

Figure 1 shows the relation between urea nitrogen synthesis rate and mean peripheral plasma $\alpha$-amino nitrogen concentration in the same sampling interval for the control persons. Observations from each individual are connected in chronological order by lines. Figure 2 gives the corresponding data for the patients with cirrhosis and the tolerance limits of the control material for comparison. The urea nitrogen synthesis rate rose linearly with the plasma amino nitrogen concentration in all cases.

By linear regression the intercept with the $\mathrm{x}$-axis was positive except for nos. 3 and 7 , significantly 


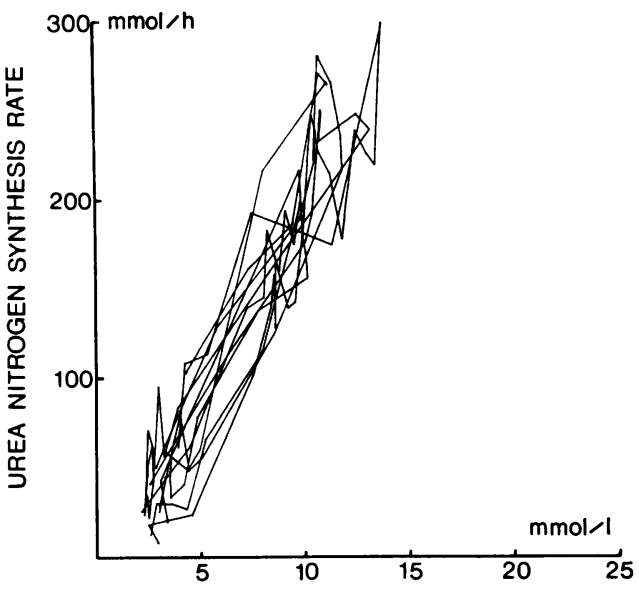

PLASMA $\propto$-AMINO NITROGEN CONCENTRATION

Fig. 1 Relation between urea nitrogen synthesis rate and peripheral plasma $\alpha$-amino nitrogen concentration in six control subjects with observations from each subject connected in chronological order by lines.

so except in nos. 2, 10, and 11. Table 3 gives the individual equations. The slope obtained in the control persons varied from 15.7 to $28.9 \mathrm{l} / \mathrm{h}$, the individual values being significantly different $\left(\mathrm{P}<0.001\right.$, regression in groups). ${ }^{12}$ The slope in the patients with cirrhosis was between 6.4 and $24.31 / \mathrm{h}$, and was, on average, $40 \%$ lower than in the control subjects $(\mathrm{P}<0.025)$.

In control subject no. 1 the investigation was repeated after an interval of one month. The slope of the second regression analysis was $24.51 / \mathrm{h}$ and not significantly different from the first one $(P>0 \cdot 10)$.

Figure 3 shows the relation of the calculated slope to the galactose elimination capacity and the clearance of antipyrine. A statistically significant

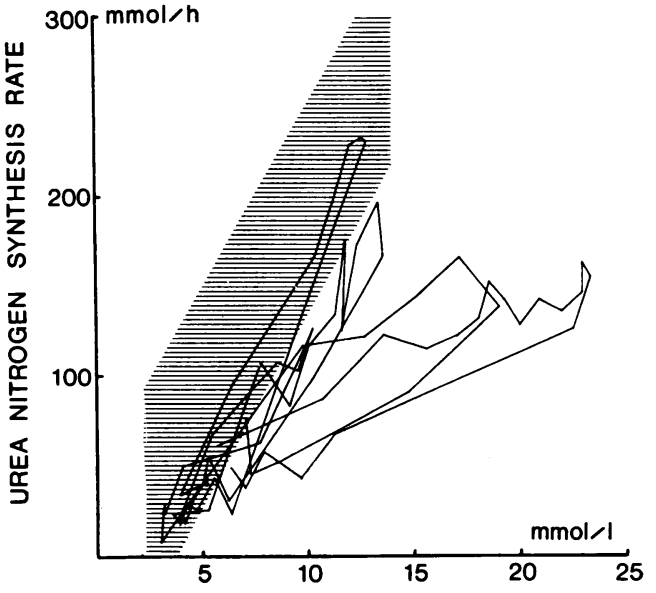

PLASMA $\propto$-AMINO NITROGEN CONCENTRATION

Fig. 2 Relation between urea nitrogen synthesis rate and peripheral plasma $\alpha$-amino nitrogen concentration in five patients with cirrhosis of the liver. Observations from each individual are connected by lines in chronological order. The hatched area indicates the $95 \%$ tolerance limits of the control material.

correlation with both liver function measures was found.

\section{Discussion}

Estimation of hepatic urea synthesis rate from $\alpha$ amino acids by the method used is based on the two assumptions that urea is eliminated only by urinary excretion and breakdown by intestinal flora, and that changes in the urea pool of the body can be accurately measured. Furthermore, interpretation of the results with respect to liver function may depend on differences of various $\alpha$-amino acids as substrates for urea formation. Both intestinal loss of

FUNCTIONAL HEPATIC NITROGEN CLEARANCE
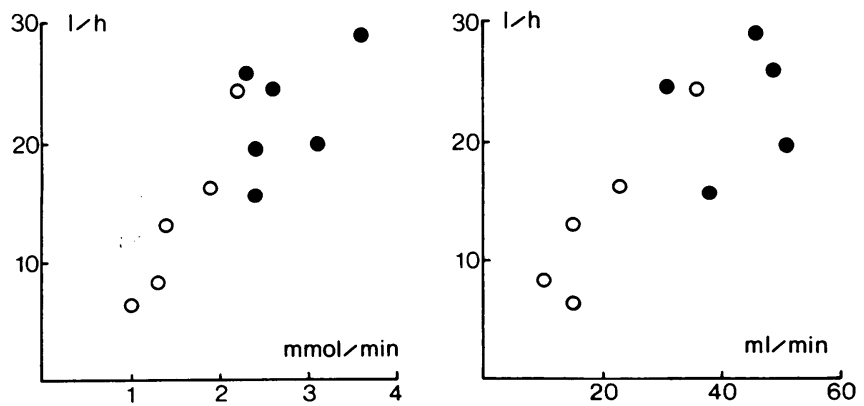

GALACTOSE ELIMINATION CAPACITY
Fig. 3 Correlation between functional hepatic nitrogen clearance $(F H N C)$ and galactose elimination capacity (GEC) $(F H N C=1.03+7.94 \times G E C(N=11)$, $r=0.84, \mathrm{P}<0.001)$ and the clearance of antipyrine (Cl.Ant.) $(\mathrm{FHNC}=5 \cdot 58+$ $0.40 \times C l$.Ant. $(N=10), r=0.80$, $\mathrm{P}<0.0025)$ to the left and the right, respectively. Interception values not significantly different from zero.

- Control subjects. OPatients with cirrhosis of the liver. 
urea and the total body water were determined less than one week before the amino load. As body weight, diet, and general clinical condition were stable during that time, probably no major changes occurred in these two measures.

The critical points of the first assumption are twofold. Firstly, the fraction of newly synthesised urea broken down by bacterial action should be relatively independent of the urea synthesis rate, as it cannot be determined simultaneously. The studies performed by Gibson et al.$^{13}$ indicate that this is the case. Secondly, ${ }^{14} \mathrm{CO}_{2}$ formed by bacterial hydrolysis of urea should not be reutilised for urea production in the liver. According to Long et al. ${ }^{14}$ reutilisation of more than half of the carbon does take place, which means that the urea breakdown is underestimated. However, urea breakdown constituted only about $13 \%$ of the urea synthesis rate and the error committed by neglecting reutilisation, therefore, is assumed to be negligible. The second assumption is related to the distribution of urea in the body. It is well established that urea is distributed in the total body water, and that this is adequately measured by antipyrine. ${ }^{15}$ However, during rapid changes in plasma urea concentration full equilibration may not be maintained. Errors arising from this source will be in opposite directions during rising and falling concentrations, respectively, and data obtained during those conditions were therefore compared. In most cases, identical urea synthesis rates were found in relation to a given plasma $\alpha$-amino nitrogen concentration at rising and falling levels, but in four (nos. 4, 7, 8, and 10) it was lower during falling concentrations. In these cases the distribution of urea in its volume of distribution therefore may have been incomplete. Other data from these studies-for example, total body water, and rate of change of urea plasma concentration-gave no clue to the phenomenon. However, if estimates are made during rising as well as during falling concentrations, the errors will tend to cancel out.

Interpretation of the observations in terms of liver function might be in terms of substrate/product conversion. This is physiologically meaningful if different amino acids are not handled differently by normal subjects and those with cirrhosis and if the conversion of all $\alpha$-amino acids involved have identical kinetic constants with respect to urea synthesis-or if one of the infused amino acids is primarily responsible for ureagenesis. Sufficient data to elaborate these assumptions are not available at the moment, but, until rejected, they are accepted as a basis for quantification. The linear relation between urea synthesis rate and $\alpha$-amino acids indicates that saturation of the urea synthesis did not take place. It suggests first order kinetics in the examined range of $\alpha$-amino nitrogen concentrations that can be described by the clearance concept. It is here designated 'functional hepatic nitrogen clearance' (FHNC) and defined as the slope of the relation between urea nitrogen synthesis rate and peripheral $\alpha$-amino nitrogen concentration with the dimension litres per hour.

This linear relationship was also found by Rafoth et al. $^{16}$ after a protein meal, increasing the plasma $\alpha$-amino concentration to $7 \mathrm{mmol} / \mathrm{l}$. The FHNC calculated from their data is on the average 17.5 $1 / \mathrm{h}$ in normal persons, which is of the same order of magnitude as the value $22.4 \mathrm{l} / \mathrm{h}$ found in the present study.

A different kinetics was presumed by Rudman et al. $^{4 \mathrm{a}}$ for estimation of 'maximal rate of urea synthesis' (MRUS), implying saturation of the urea synthesis rate at plasma $\alpha$-amino concentrations above $11 \mathrm{mmol} / 1 .{ }^{17}$ However, the calculated urea synthesis rate in that study, assumed to be maximal, is only $50 \%$ of the highest synthesis rate seen in the present investigation. One explanation of this discrepancy may be that the criterion for saturation of the urea synthesis rate used by Rudman et al. was that the urinary excretion of urea did not rise further when the load of protein or amino acids exceeded a certain level. This was also observed in five cases of the present study, but the estimated urea synthesis rate continued to rise with the plasma $\alpha$-amino nitrogen concentration because of rapid accumulation. Thus the phenomenon may reflect a maximum urinary urea excretion rate at a given urine flow. Furthermore MRUS was measured at least eight hours after the start of the amino acid infusion, at which time equilibrium between infusion rate of amino nitrogen and urea synthesis is attained. The decreased MRUS in the patients with cirrhosis therefore is probably due to the lower infusion rate of amino acids used in these patients. The data of Rudman et al. are in agreement with our observations, in so far as approximately similar urea synthesis rates were obtained at comparable $\alpha$ amino nitrogen concentrations. In accordance, members of Rudman's group have recently reported results using a kinetic urea tracer method indicating that the 'maximal' rate of urea synthesis was not obtained in the earlier investigations. ${ }^{18}$ It is reasonable to assume that hepatic urea synthesis is a saturable process, but apparently maximum rates require $\alpha$-amino nitrogen concentrations that are unfeasibly high in clinical studies because of the nausea and vomiting that they cause.

One difficulty in applying the clearance concept to urea synthesis from $\alpha$-amino acids is that urea synthesis is zero at a positive $\alpha$-amino nitrogen concentration (on the average $1.7 \mathrm{mmol} / \mathrm{l}$ ). This 
may reflect a nitrogen sparing or anabolic mechanism. The exception to this was seen in cases who may have been in a catabolic state, in one patient (no. 3) this was caused by a low caloric diet for treatment of obesity, and one (no. 7) by prednisone treatment. This indicates that the kinetics of urea synthesis reflects, not only liver function, but also other metabolic regulations, including hormonal status. It is well known, for example, that glucagon may stimulate urea cycle hormones, ${ }^{19}$ but the significance of this for the FHNC remains to be studied. It follows, therefore, that the importance of the concomitant infusion of glucose or lactate to five subjects in this study is uncertain.

The good agreement between the FHNC and quantitative measures of liver function, such as the galactose elimination capacity and the clearance of antipyrine, underscores the importance of liver function for the urea synthesis rate. Whether the FHNC is another indicator of the 'functional liver mass' with potentialities of its own is not as yet known.

The patients with cirrhosis were able to cope with the large amino nitrogen loads given, confirming the abundant capacity of the urea synthesis system. A given synthesis rate in the patient, however, required concentrations of $\alpha$-amino nitrogen higher than in the control subjects. Thus, equilibrium between supply and removal of nitrogen was attained at a higher concentration level of amino acids. This may play a part in the clinical manifestations of hepatic insufficiency.

Technician Bjoerg Krog is thanked for expert laboratory work, nurses of the department for meticulous care with the blood and urine specimens, and Dr P Buch Andreasen for providing the facilities for the antipyrine measurements. The work was supported by grants from F L Smidth and Co. Ltd Commemorative Foundation.

\section{References}

${ }^{1}$ Levin B. Hereditary metabolic disorder of the urea cycle. Adv Clin Chem 1971; 14: 65-143.

${ }^{2}$ Rabinowitch JM. Biochemical findings in a rare case of acute yellow atrophy of the liver. J Biol Chem 1929; 83: 333-5.

${ }^{3}$ Ansley JD, Isaacs JW, Rikkers LF, et al. Quantitative tests of nitrogen metabolism in cirrhosis: relation to other manifestations of liver disease. Gastroenterology 1978; 75: 570-9.

${ }^{4}$ Rikkers L, Jenko P, Rudman D, et al. Subclinical hepatic encephalopathy: detection, prevalence, and relationship to nitrogen metabolism. Gastroenterology; 75: 462-9.

${ }^{4 a}$ Rudman D, DiFulco TJ, Galambos JT et al. Maximal rates of excretion and synthesis of urea in normal and cirrhotic subjects. J Clin Invest 1973; 52 : 2241-9.

${ }^{5}$ Fawcett JK, Scott JE. A rapid and precise method for the determination of urea. J Clin Path 1960; 13: 156-9.

${ }^{6}$ Goodwin JF. Spectrophotometric quantitation of plasma and urinary amino nitrogen with fluorodinitrobenzene. Stand Meth Clin Chem 1970; 6: 89-98.

${ }^{7}$ Fonseca-Wollheim VFD. Bedeutung von Wasserstoffionenkonzentration und ADP-zusatz bei der Ammoniakbestimmung mit Glutamatdehydrogenase. $Z$ Klin Chem Klin Biochem 1973; 11 : 421-5, 426-31.

${ }^{8}$ Tygstrup N. Determination of the hepatic elimination capacity $(\mathrm{Lm})$ of galactose by single injection. Scand $J$ Clin Lab Invest 1966; 18: 118-25.

${ }^{9}$ Andreasen PB, Ranek L, Statland BE, Tygstrup N. Clearance of antipyrine-dependence of quantitative liver function. Europ J Clin Invest 1974; 4: 129-34.

${ }^{10}$ Soberman R, Brodie BB, Levy BB, et al. The use of antipyrine in the measurement of total body water in man. J Biol Chem 1949; 179: 31-42.

${ }^{11}$ Walser M, Bodenlos LJ. Urea metabolism in man. J Clin Invest 1959; 38: 1617-26.

${ }^{12}$ Armitage P. Statistical methods in medical research. Oxford: Blackwell Scientific Publications, 1977.

${ }^{13}$ Gibson JA, Parks NJ, Sladen GE, et al. The role of the colon in urea metabolism in man. Clin Sci Mol Med 1976; 50: 51-9.

${ }^{14}$ Long CL, Jeevanandam M, Kinley JM. Metabolism and recycling of urea in man. Am J Clin Nutr 1978, 31 : 1367-82.

${ }^{15}$ Williams RE, Smith AH, Young GA, et al. Experimental comparison of the rates and volumes of distribution of urea, creatinine, $\mathrm{N}$-acetyl-4-aminophenazone, and tritiated water. Br J Surg 1964; 51: 544-9.

${ }^{16}$ Rafoth RF, Onstad GR. Urea synthesis after oral protein ingestion in man. J Clin Invest 1975; 56: $1170-4$.

${ }^{17}$ Galambos JT, Warren WD, Rudman D, et al. Selective and total shunts in the treatment of bleeding varices. N Engl J Med 1976; 295: 1089-95.

${ }^{8}$ Rypins EB, Henderson JM, et al. A tracer method for measuring rate of urea synthesis in normal and cirrhotic subjects. Gastroenterology 1980; 78: 1419-24.

${ }^{19}$ Snodgrass PJ, Lin Rc, et al. Induction of urea cycle enzymes of rat liver by glucagon. J Biol Chem 1978; 253: 2748-53. 